\title{
Why we should stop using animal-derived products on patients without their consent
}

\author{
Daniel Rodger
}

\section{Correspondence to}

Daniel Rodger, Institute of

Health and Social Care, London

South Bank University, School of

Allied and Community Health,

London SE1 OAA, UK;

daniel.rodger@|sbu.ac.uk

Received 1 March 2021

Accepted 14 May 2021

Check for updates

(C) Author(s) (or their employer(s)) 2021. No commercial re-use. See rights and permissions. Published by BMJ.

\section{To cite: Rodger D.}

$J$ Med Ethics Epub ahead of

print: [please include Day

Month Year]. doi:10.1136/

medethics-2021-107371

\section{ABSTRACT}

Medicines and medical devices containing animal-derived ingredients are frequently used on patients without their informed consent, despite a significant proportion of patients wanting to know if an animal-derived product is going to be used in their care. Here, I outline three arguments for why this practice is wrong. First, I argue that using animal-derived medical products on patients without their informed consent undermines respect for their autonomy. Second, it risks causing nontrivial psychological harm. Third, it is morally inconsistent to respect patients' dietary preferences and then use animal-derived medicines or medical devices on them without their informed consent. I then address several anticipated objections and conclude that the continued failure to address this issue is an ethical blind spot that warrants applying the principles of respect for autonomy and informed consent consistently.

\section{INTRODUCTION}

Western countries have become increasingly diverse and multicultural, and the population holds a variety of religious and secular beliefs about the use of animals in food, clothing, research, and medical products. The number of individuals with such dietary preferences has increased steeply in recent years as have those with concerns about the use of animal-derived products in healthcare. By an animalderived product in healthcare, I mean any medicine or medical device-implant, suture, dressing, tissue graft, vaccine- that contains an animal-derived ingredient. The scale of this problem is significant-of the 100 most prescribed drugs in primary care in the UK, 74 contained an animal-derived product. ${ }^{1}$

These concerns are not new-more than 1700 years ago the Hellenistic philosopher Plotinus, who was a vegetarian, refused medicines with animal substances. ${ }^{2}$ For Muslims, products containing animalderived products are unlikely to be halal-compatible with Islamic dietary laws. In 2017, the Muslim population in the USA was estimated at 3.45 million and is expected to represent $2 \%$ of the population by $2050^{3}$; in the UK in 2018, the Muslim population numbered over 3.3 million. ${ }^{4}$ Hindus are also another significant group that have dietary preferences, and number over 1 million in the UK. ${ }^{4}$ Furthermore, research commissioned by The Vegan Society found that over 500000 of the over-15 population in the UK follow a vegan diet, which amounts to more than a 300\% increase since 2006-a significant proportion of who avoid nondietary animal products. ${ }^{5}$ i Similar trends have occurred in the USA where it is estimated that there

${ }^{\mathrm{i}}$ In further support of this trend, in 2020 every UK supermarket has its own vegan range, and most top restaurants have a vegan or plant-based option. are now more than 9 million vegans, accounting for $3 \%$ of the population. ${ }^{6}$

It is routine in liberal societies for hospital inpatients to be asked about their dietary preferences to avoid providing food that conflicts with their beliefs. There is no expectation that patients must self-declare this information. Patients expect to have their dietary preferences respected, and for a patient to be given something that contravenes their wishes would be understood to have caused harm. For instance, there are examples of vegetarians accidentally given meat who have described their experiences in traumatising terms-feeling 'defiled'. A concern is that many patient's dietary preferences may also be reflected in their beliefs about the use of animal-derived products used in other contexts-such as healthcare-and that this is a problem that is not currently getting the attention it deserves.

If a problem does exist, then it is on a remarkable scale, with potentially hundreds of thousands of patients each year in the UK receiving animal-derived products to which they never consented. There are a growing number of ethicists and clinicians-such as surgeons and pharmacists-who argue that the principle of informed consent entails that the use of animal-derived products should be disclosed to patients. ${ }^{8-11}$ However, there are several challenges to satisfy this commitment. First, many clinicians may be unaware of all the medicines and medical devices that contain an animal-derived product, and this information is not always easily accessible and sometimes unclear or incorrect. ${ }^{1}$ Second, it would also require clinicians to know whether there was a nonanimal-derived alternative available. In many jurisdictions, pharmaceutical companies are only required to record the active ingredients and not the excipients, despite typically making up $90 \%$ of the formulation of a drug-this is something that would need to change. ${ }^{11}$ Only then, can there be greater transparency on the labelling of medicines and medical devices. These problems are not easily navigated and would require significant local and national change.

It is not far-fetched to believe that some people would feel upset to discover that animal-derived products were used in their care-or their child's without their consent. I argue that there are good ethical reasons for clinicians to begin routinely disclosing to patients where a known animalderived product is intended to be used, administered, or prescribed. I conclude by showing that respect for autonomy and informed consent are being applied inconsistently and that the disclosure of animal-derived products should become routine practice. 


\section{DO PATIENTS WANT TO KNOW?}

Dietary preferences will not necessarily translate into concerns about the use of animal-derived products in healthcare. Nevertheless, research exploring this question has consistently shown that many patients would object to the use of certain animalderived products in their care, while others only want the opportunity to give their informed consent.

A study conducted in the USA surveyed the views of 100 patients on animal-derived products in medication, and $63 \%$ wanted to be informed about their use by their physician. ${ }^{12}$ The importance of disclosure is evidenced in several case studies, where the failure to disclose the presence of excipient animalderived products in medication led to nonadherence, relapse and hospitalisation. ${ }^{13}$ A survey of 13 representative religious leaders in the UK showed that $77 \%$ believed that consent should be gained from patients for skin substitutes and dressings that contain a biological product. ${ }^{14}$ This is congruent with the views expressed by international religious leaders. ${ }^{15}$

A survey of 534 patients in three West Midlands otolaryngology outpatient departments found that $44 \%$ wanted to be informed about the use of biological products-primarily animal-derived products-if they underwent surgery and 17\% objected to the use of any biological products during surgery. ${ }^{16}$ Even in an emergency, $7 \%$ of patients would not accept a biological product, further highlighting the significance, this has for many patients. Most objections against the use of biological products were predicated on religious grounds, however, $11 \%$ of atheists also objected. The latter observation is unsurprising as there exists a strong correlation between atheism and veganism-in one survey of American vegans more than $50 \%$ self-identified as atheists. ${ }^{17}$ A study of patients at a US Dermatology centre showed that $74 \%$ of patients wanted to know if an animal-derived product would be used on their skin. Furthermore, for $40 \%$ of patients, the presence of an animalderived product in their sutures would affect their treatment preferences. $^{18}$

The evidence strongly supports the contention that patients' ethical or religious dietary concerns can extend to the use of animal-derived products in healthcare. The studies that have been conducted so far consistently show that a significant proportion of patients want to be informed about the use of animal-derived products in their care.

\section{DISRESPECT FOR AUTONOMY}

Since the late 1970s respect for patient autonomy has been one of the fundamental ethical principles that undergirds the patient-clinician relationship, ensuring that decisions about a patient's care are made collaboratively rather than paternalistically ${ }^{\text {ii }}$. A valid consent process requires sufficient and understandable information to be conveyed that is relevant to his or her decision. ${ }^{19}$ Prior to the Montgomery v Lanarkshire Health Board (2015) ruling in the UK clinicians were free to disclose information to patients that they believed was relevant based on their clinical expertise and judgement. ${ }^{20}$ However, since the Montgomery ruling, clinicians are expected to tell patients what they want to know and not just what they think they should be told-it established a duty of care to make patients aware of any material risks. A material risk describes a risk that a patient would ascribe significance to: 'a reasonable person in the

${ }^{\mathrm{ii}}$ Though it is worth noting that respect for autonomy may not be necessary to guard against paternalism, see Saad. ${ }^{41}$ patient's position would be likely to attach significance to the risk, or the doctor is or should reasonably be aware that the particular patient would be likely to attach significance to it'. ${ }^{21}$ Despite the immediate context referring to the risks associated with a medical procedure, it is not unreasonable to conclude that a patient may ascribe significance to unknowingly having an animal-derived product used in their medical treatment. iii

Wanting to be informed about the use of animal-derived products may seem like an unconventional belief, however Tom Beauchamp and James Childress argue-'to respect autonomous agents is to acknowledge their right to hold views, make choices and to take actions based on their values and beliefs'. ${ }^{22}$ Arguably, by not considering the significance that many patients would attach to this belief, a substantial number of patients are routinely having their autonomy disrespected. ${ }^{9}$ Moreover, not only does the Montgomery ruling provide prima facie support for the disclosure of animal-derived products to patients but so does the ethical guidance from the General Medical Council (GMC). The GMC recommends that patients' cultural, religious and other beliefs and values are considered when treating them. ${ }^{23}$ The decision to avoid animal-derived products can be an expression of religious or secular values that if violated can lead to patient harm, and by not considering the impact of this, it is not clear that this guidance is being adhered to clinicians.

Many patients want to be given the opportunity to give their informed consent and failure to ask a clinician should not be considered tacit consent to their use. There may well be procedural challenges in identifying patients who would attach significance to the use of animal-derived products. Here, I only argue what ethical consistency ought to demand and not how it should be actioned in practice, while acknowledging the significant challenges that would be involved in achieving this. There are also further complicating factors, for instance, what about parents of children who do not want the most efficacious treatment to be used because it contains an animal-derived product? ${ }^{\text {iv }}$ In one case, a 14-year-old child had their successful skin graft removed after their Muslim parents later discovered it contained porcine-derived products. This subsequently led to a significant loss of function in the child's arm. ${ }^{24} 25$ v Importantly, if the use of an animal-derived product had been explained to the parents during the consent process, an alternative treatment could have been explored and the negative outcome prevented.

\section{NONTRIVIAL PSYCHOLOGICAL HARM}

The history of medicine is replete with examples of psychological harm caused to patients when certain information was withheld from them-importantly this information would have been in their interest to know. For instance, the practice of performing educational pelvic examinations under general anaesthesia without informed consent. ${ }^{26}$ Harm is commonly understood as the wrongful setback to a person's interests. ${ }^{27}$ In medical ethics, the principle of nonmaleficence states that there is an obligation not to cause unnecessary harm to others. ${ }^{22}$ There are many ways in which clinicians can harm their patients, with negligence in performing a procedure being the most obvious example.

\footnotetext{
${ }^{\text {iii }}$ Or in a drug they are prescribed.

${ }^{\text {iv }}$ Similar issues have arisen in England where some Muslim parents have refused to let their children receive the nasal influenza vaccine Fluenz because it contains porcine gelatine. ${ }^{42}$

${ }^{v}$ For a comprehensive exploration of the problems associated with moral pluralism in secular clinical ethics, see Brummett ${ }^{43}$, and Hassanein and Anderson. ${ }^{28}$
} 
However, harm can also be inflicted by failing to disclose information to patients which was in their interest to know, resulting in a course of action that the patient may not have agreed to had the information been disclosed. The most common example of this is the failure to disclose the potential risks and complications of a procedure. There are, however, less obvious ways of harming patients by failure to disclose information. For example, Jehovah's Witness adherents have a strong religious objection to receiving allogeneic blood transfusions, and if a transfusion is administered without their consent, psychological harm could result when they become aware of it.

Another example of psychological harm potentially being caused to patients is when clinicians use animal-derived products on them without their informed consent. Despite some discussion in the literature over the last decade, ${ }^{7-11} 151828-31$ the use of animalderived products on patients without their consent is a practice that largely continues unencumbered. This is despite the risk of causing nontrivial psychological harm to patients who later discover this occurred.

\section{Scenario 1}

A Muslim patient is admitted for an elective hernia repair and because of some pre-existing health conditions is admitted as an inpatient the evening prior to his surgery. Shortly after arrival on the ward, he is asked whether he has any dietary preferences, and he notes that as a Muslim he will eat only food that is Halal and will not eat pork. The following morning, the surgeon arrives to consent the patient and they agree that a mesh will be used for the hernia repair. The surgery is completed without incident and the patient is discharged later that evening. After the surgery, the patient discovers that a biologic hernia mesh derived from porcine dermis was used and feels angry and defiled.

In this scenario, the patient's wishes not to eat pork are treated with respect while these preferences are disregarded with respect to his surgery. It remains unclear why one preference should be routinely respected and the other should not; the psychological harm caused by failing to disclose the use of animal-derived products may be similar or equal to not respecting a patient's dietary preferences. Discussing the presence of an animalderived product in the consent process would have provided an opportunity to explore alternative hernia meshes and avoid the psychological harm caused. Perhaps an alternative hernia mesh would be less efficacious but that remains the patients choice and clinicians are obligated to discuss reasonable alternatives and explain the implications of doing so.

\section{Scenario 2}

A vegan patient receives the first of two COVID-19 vaccine doses and it is administered without any issues. However, a week later, she discovers that the vaccine was tested on rhesus macaques and mice. This was never disclosed to her or described in the patient leaflet. ${ }^{32}$ She is distressed to discover this and subsequently decides that she will not accept the second dose of the vaccine.

Compared with scenario 2, there is nothing in the vaccine itself that is animal derived ${ }^{\text {vi }}$. However, it is not currently legal to complete human vaccine trials without first completing testing on animals and so animals would have been harmed in this process. On first appearances, this may seem outlandish, however, some vegans have argued that they will not accept any COVID-19 vaccine that 'exploits' animals, irrespective of how serious the pandemic is. ${ }^{33}$ vii Importantly, ethical vegans are now

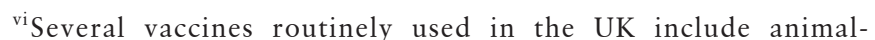
derived products, for instance, Fluenz Tetra, MMR VaxPro, and Zostavax all contain porcine.
}

${ }^{\text {vii }}$ The Vegan Society released a statement that highlights how recognised as having philosophical beliefs that are protected characteristics under the Equality Act $2010 .^{34}$ Compared with the first scenario, there is no alternative available and the only option for someone with this concern is to either accept that using any medication requires a degree of compromise or reject the vaccine outright. ${ }^{\text {viii }}$ Despite there being no acceptable alternative vaccine available, this does not remove the obligation to disclose information that would have significance to a particular patient. If a Jehovah's Witness patient requires a life-saving allogeneic blood transfusion, there may be no alternative ${ }^{i x}$ and yet the principles of nonmaleficence and respect for autonomy require their informed consent. The fact that alternatives do not exist does not remove the requirement for informed consent.

It is not prima facie unreasonable for individuals to want to know about the origins-testing, development, and ingredients-of a vaccine. The origins of a vaccine or any other medicines may have moral significance to many people. For instance, human embryonic kidney cells were used during testing of some COVID-19 vaccines, ${ }^{35}$ and yet despite the moral significance of this practice, it is not routinely disclosed or information that is easily accessible. There are obvious concerns with doing sosome individuals may decide to decline vaccination leading to a decline in vaccination rates. However, rather than ignoring these concerns and allowing misinformation and conspiracy theories to flourish, ${ }^{36}$ a more transparent approach rooted in accurate disclosure may help to alleviate vaccine hesitancy rather than worsen it. ${ }^{x}$

\section{ETHICAL BLIND SPOT}

Why do hospitals respect ethical and/or religious beliefs when it comes to dietary preferences, but then use medicines and medical devices that seemingly contravene those same beliefs without routinely disclosing it to patients? There is not any obvious ethical principle that applies in one scenario but not in the other. Perhaps this moral inconsistency is an example of benevolent paternalism-because routine disclosure of the presence of animal-derived products risks causing patient harm. There are two obvious risks to the patient: first, there may be no alternative treatment; and second, the alternative could have a reduced efficacy. In the case of respecting patient's (or patients') dietary preferences, alternatives can always be provided, but, in the case of medicines and medical devices, this is not always possible. If no alternative is available, then disclosure risks instigating a cascade of events that could lead a patient to reject a treatment that would otherwise be in their best interest to receive. However, we cannot pick and choose how or when we respect autonomy, even if doing so risks leading to an undesirable outcome. Respecting a patient's autonomy means having to respect their right to make decisions based on their own ethical values or religious beliefs, even if we might disagree with the likely outcome of that decision.

stressful and upsetting it can be to compromise their beliefs and that everyone should make an informed decision ${ }^{44}$

${ }^{\text {viii }}$ The latter could be understood as a way to strongly encourage the scientific community to explore and develop effective alternative non-animal research methods.

${ }^{\text {ix }}$ Apart from the use of intraoperative cell salvage.

${ }^{\mathrm{x}}$ The failure of public transparency and individual disclosure is likely to have helped to facilitate an increase in anti-vaccine sentiment and vaccine hesitancy-a particular concern during the COVID-19 pandemic. 
An alternative explanation for this inconsistency is that it is a kind of ethical blind spot. An ethical blind spot is a lack of awareness that obscures the ability to recognise certain morally relevant features of a situation. ${ }^{37}$ In this case, the relevant ethical principles are being rightly applied in one context-dietary preferences-but there is a lack of awareness of their application in the context of medicines and medical devices. On the one hand, respect for autonomy is considered one of the core ethical principles of medical ethics and yet it is frequently inconsistently applied with respect to the use of animal-derived products. This is an ethical failure, but, I do not intend to impart moral guilt; instead, I only want to expose the ethical blind spot, so that important ethical principles can be applied fairly to all patients.

\section{POTENTIAL OBJECTIONS AND RESPONSES}

Here, I address several possible objections against disclosing difficulties with my proposal are related to the consequences of disclosure and whether patients' expectations can be

\section{Economic cost objection}

Informing patients that products used in their care may include animal-derived products might incur a significant economic cost at a time when health services are already under significant financial pressures.

In response, it is possible that the disclosure of animal-derived products could result in increased economic costs. Additional costs would most likely result from the use of more expensive alternatives. In some cases, the additional cost of some alternatives could financially impact service provision. However, it is not obvious that the obligation to disclose entails an obligation to provide costly alternatives or for patients to demand them. It seems reasonable to absorb some additional costs to avoid causing harm to patients, but this will ultimately have a limit to ensure the fair distribution of health resources. Therefore, it may not be possible to accommodate all the available alternatives due to the limited resources available. This means that in some cases, patients may be left with a troubling decision-compromise their ethical and/or religious beliefs or forgo the intended benefits of the treatment or medication. It will be the responsibility of healthcare services to decide how they balance the obligation to respect patient autonomy with any additional costs this may incur.

\section{Patient refusal objection}

If the presence of an animal-derived product in a treatment is disclosed to a patient, they might refuse the treatment, thereforedenying the patient of the intended health benefits.

This objection is one of the primary troubling implications of what I am proposing. There is research showing that some individuals would refuse prescribed oral medication if it contained animal-derived ingredients, even if there was no alternative treatment available. ${ }^{38}$ Yet, provided the patient can make an informed decision, it is their prerogative to refuse treatment-this is the nature of informed consent. Furthermore, there is evidence that most patients who object to the routine use of animal-derived products in their care will accept such treatment in an emergency, or when no alternative exists ${ }^{1529}$ xi . Nevertheless, some patients the use of animal-derived products to patients. The primary accommodated.

may decide that they do not want animal-derived products used in their care and even if a suitable alternative cannot be found, the patient's autonomy must still be respected.

Failure to disclose, the presence of animal-derived products also risks facilitating medication nonadherence, which can result in several negative outcomes ${ }^{\mathrm{xii}} .{ }^{13}$ First, medication non-adherence to antibiotics or anticoagulants can in some cases cause relapse, worsening of symptoms and an increased mortality risk. ${ }^{39}$ Second, it may compound the existing scepticism of the medical community, leading to increased disengagement with healthcare services. Furthermore, when explaining any risks, a treatment poses during the standard informed consent process, there is already a possibility that doing so could result in a patient declining the proposed treatment and its intended benefits.

\section{Time constraints objection}

Informing patients that products used in their care may include animal-derived ingredients will require additional time demands on clinicians who are already under significant time restraints.

It seems self-evident that disclosing the use of animalderived products will increase demands on a clinician's time. In most cases, patients will likely not have any objections, but in a minority of cases, this could amount to a significant demand on their time. Arguably, as disclosure is normalised, it is likely that those time demands are likely to decrease as patients themselves become more informed about the relevant issues. Ultimately, if the use of animal-derived products ought to be disclosed, then the additional demands on time are not sufficient to outweigh doing so. This is because many patients may not know that medicines and medical devices can contain animal-derived products and because they could attach significance to it, disclosure would allow them to ask the types of questions they would have done if they had known. ${ }^{40}$ However, like any other limited resource, clinician time must be distributed fairly and balanced against patient need to ensure maximising benefits to all patients. This highlights the challenges involved with balancing respect for autonomy with nonmaleficence and there are often no wholly satisfying outcomes.

\section{CONCLUSION}

A growing number of patients want to know whether animalderived products are used in their care. Patients' ethical or religious dietary preferences in many cases do extend to the use of animal-derived products in healthcare and the failure to address this issue is an ethical blind spot. Currently, there remains a lack of consistency regarding whether patients are informed about the use of animal-derived products despite the risk of psychological harm, failure to respect autonomy and the implications of the Montgomery ruling. These are significant concerns that warrant a change in practice to routine disclosure. However, doing so, risks opening a Pandora's box of challenges that are neither insubstantial nor easily resolved. Once there is agreement that this problem needs addressing, it will take a collaborative approach to navigate the challenges to satisfying this commitment. Despite some of the troubling implications of my argument, the status quo is also troubling.

\footnotetext{
${ }^{x i}$ An example of this is a precedent in Islamic teaching that permits the use of otherwise prohibited ingredients when there is no alternative, see Ali and Maravia. ${ }^{45}$
}

${ }^{x i i}$ Patients in these case studies were subsequently prescribed medication that did not contain an animal-derived product. 
Twitter Daniel Rodger @philosowhal

Acknowledgements The author thanks Michal Pruski, Toni Saad, Bruce Blackshaw, David Rassam, Nathan Nobis, and Usman Maravia for their helpfu feedback when preparing this manuscript.

Contributors DR is the sole author.

Funding The authors have not declared a specific grant for this research from any funding agency in the public, commercial or not-for-profit sectors.

Competing interests None declared.

Patient consent for publication Not required.

Provenance and peer review Not commissioned; externally peer reviewed.

Data availability statement There are no data in this work.

ORCID iD

Daniel Rodger http://orcid.org/0000-0002-2121-7167

\section{REFERENCES}

1 Tatham KC, Patel KP. Suitability of common drugs for patients who avoid animal products. BMJ 2014;348:g401.

2 Porphyry. On the life of Plotinus and the arrangement of his work. Trans: MacKenna S Edmonds: Alexandrian Press, 1984

3 Mohamed B. New estimates show U.S. Muslim population continues to grow, 2018. Pew Research Center. Available: https://www. pewresearch.org/fact-tank/2018/01/ 03/new-estimates-show-u-s-muslim-population-continues-to-grow/ [Accessed Feb 2021].

4 Muslim population in the UK, 2018. Available: https:/wwww.ons.gov.uk/aboutus/ transparencyandgovernance/freedomofinformationfoi/muslimpopulationintheuk/ [Accessed Apr 2021].

5 The Vegan Society. Find out how many vegans are in Great Britain, 2016. Available: https://www.vegansociety.com/whats-new/news/find-out-how-many-vegans-aregreat-britain [Accessed Feb 2021].

6 Reinhart RJ. Snapshot: few Americans vegetarian or vegan. Gallup, 2018. Available: https://news.gallup.com/poll/238328/snapshot-few-americans-vegetarian-vegan. aspx?g_source=link_NEWSV9\&g_medium=NEWSFEED\&g_campaign $=i t e m ~ \& q$ content=Snapshot $\% 3 a \% 2520$ Few\% 2520 Americans $\% 252$ VVegetarian $\% 2520$ or $\%$ 2520Vegan [Accessed Feb 2021].

7 Levy N. Vegetarianism: toward ideological impurity. In: Bramble B, Fischer B, eds. The moral complexities of eating meat. New York: Oxford University Press, 2015: 172-84.

8 Phelan PS, Council ML. Ethical considerations in the use of biopolymer sutures. $J$ Dermatolog Treat 2019;30(4):350-1.

9 Rodger D, Blackshaw BP. Using animal-derived constituents in anaesthesia and surgery: the case for disclosing to patients. BMC Med Ethics 2019;20(1):14.

10 Koshy RM, Kane EG, Grocock C. A review of the use of biological mesh products in modern UK surgical practice: a religious and cultural perspective. Ann R Coll Surg Engl 2020;102(8):566-70.

11 Page A, Etherton-Beer C. Choosing a medication brand: excipients, food intolerance and prescribing in older people. Maturitas 2018:107:103-9.

12 Sattar SP, Ahmed MS, Madison J, et al. Patient and physician attitudes to using medications with religiously forbidden ingredients. Ann Pharmacother 2004;38(11):1830-5.

13 Sattar SP, Shakeel Ahmed M, Majeed F, et al. Inert medication ingredients causing nonadherence due to religious beliefs. Ann Pharmacother 2004;38(4):621-4.

14 Enoch S, Shaaban H, Dunn KW. Informed consent should be obtained from patients to use products (skin substitutes) and dressings containing biological material. J Med Ethics 2005:31(1):2-6.

15 Eriksson A, Burcharth J, Rosenberg J. Animal derived products may conflict with religious patients' beliefs. BMC Med Ethics 2013;14:48.

16 Jolly K, Darr A, Aslanidou A, et al. The intra-operative use of biological products: a multi-centre regional patient perspective of a potential consenting conundrum. Clin Otolaryngol 2019;44(5):831-5.

17 Wrenn CL. Atheism in the American animal rights movement: an invisible majority. Environ Values 2019;28(6):715-39.
18 Bentivegna K, DeWane ME, Parikh SA, et al. Animal product in suture material: A survey study of dermatology patient perspectives. J Am Acad Dermatol 2020;83(3):907-8

19 Seay G, Nuccetelli S. Engaging bioethics: an introduction with case studies. New York: Routledge, 2017

20 Chan SW, Tulloch E, Cooper ES, et al. Montgomery and informed consent: where are we now? BMJ 2017:357.

21 Montgomery v Lanarkshire Health Board [2015] SC 11 [2015] 1 AC 1430. Available: https://www.bailii.org/uk/cases/UKSC/2015/11.html [Accessed Feb 2021].

22 Beauchamp TL, Childress JF. Principles of biomedical ethics. 7th edn. New York: Oxford University Press, 2013.

23 General Medical Council. Personal beliefs and medical practice, 2013. Available: https://www.gmc-uk.org/ethical-guidance/ethical-guidance-for-doctors/personalbeliefs-and-medical-practice [Accessed Feb 2021].

24 Linnard-Palmer L, Kools S. Parents' refusal of medical treatment based on religious and/or cultural beliefs: the law, ethical principles, and clinical implications. J Pediatr Nurs 2004;19(5):351-6.

25 Linnard-Palmer L. When parents say no: religious and cultural influences on pediatric healthcare. Indianapolis: Sigma Theta Tau International, 2006.

26 Friesen P. Educational pelvic exams on anesthetized women: why consent matters. Bioethics 2018:32(5):298-307.

27 Feinberg J. The moral limits of the criminal law, volume 1: harm to others. New York: Oxford University Press, 1984.

28 Hassanein $\mathrm{M}$, Anderson JA. Refusal of animal-derived medical products in a paediatric setting: ethical issues. Paediatr Child Health 2020:pxz171.

29 Easterbrook C, Maddern G. Porcine and bovine surgical products: Jewish, Muslim, and Hindu perspectives. Arch Surg 2008;143(4):366-70.

30 Shiwani MH. Surgical meshes that contain bovine or porcine products should be labelled. BMJ 2011:343:d4625

31 Corfield L, Granne I. Ethical and practical considerations in prescribing animal-derived medication. Postgrad Med J 2012;88(1043):497-8.

32 Pfizer Inc. Pfizer and BioNTech announce data from preclinical studies of mRNA-based vaccine candidate against COVID-19, 2020. Available: https://www.pfizer.com/news/ press-release/press-release-detail/pfizer-and-biontech-announce-data-preclinicalstudies-mrna [Accessed Feb 2021].

33 Newkey-Burden C. The ugly truth about coronavirus vaccine testing, 2020. HuffPost. Available: https://www.huffingtonpost.co.uk/entry/coronavirus-vaccine-animals_uk 5faa9c6bc5b64c88d405023e [Accessed Feb 2021]

34 Gayle D. Ethical veganism is a belief protected by law, tribunal rules, 2020. The Guardian. Available: https://www.theguardian.com/lifeandstyle/2020/jan/03/ethicalveganism-is-a-belief-protected-by-law-tribunal-rules [Accessed Feb 2021]

35 Vogel A, Kanevsky I, Che Y. A prefusion SARS-CoV-2 spike RNA vaccine is highly immunogenic and prevents lung infection in non-human primates. bioRxiv 2020:1-38.

36 Nuzhath T, Tasnim S, Sanjwal RK. COVID-19 vaccination Hesitancy, misinformation and conspiracy theories on social media: a content analysis of Twitter data. SocArXiv 2020.

37 Bazerman M, Tenbrunsel A. Blind Spots: Why We Fail To Do What's Right and What To Do About It. Princeton: Princeton University Press, 2011.

38 Vissamsetti B, Payne M, Payne S. Inadvertent prescription of gelatin-containing oral medication: its acceptability to patients. Postgrad Med J 2012;88(1043):499-502.

39 Mayor S. Non-adherence to medication increases stroke risk in patients with high blood pressure. BMJ 2013:347:f4586

40 Newson AJ. Clinical ethics Committee case 9: should we inform our patient about animal products in his medicine? Clin Ethics 2010;5(1):7-12.

41 Saad TC. The history of autonomy in medicine from antiquity to principlism. Med Health Care Philos 2018;21(1):125-37.

42 Taylor R. Muslims join official talks over pork-derived gelatine in flu vaccine, 2019. The Times. Available: https://www.thetimes.co.uk/article/muslims-join-official-talksover-pork-derived-gelatine-in-flu-vaccine-pz89fd8tf [Accessed Feb 2021].

43 Brummett AL. Secular clinical Ethicists should not be neutral toward all religious beliefs: an argument for a Moral-Metaphysical Proceduralism. Am J Bioeth 2020:1-18.

44 The Vegan Society. Vegan Society response to Covid-19 vaccine, 2020. Available: https://www.vegansociety.com/news/news/vegan-society-response-covid-19-vaccine [Accessed Feb 2021].

45 Ali M, Maravia U. Seven faces of a Fatwa: organ transplantation and Islam. Religions 2020;11(2). 